\title{
A Hydrogel Material for Plastic and Reconstructive Applications Injected into the Subcutaneous Space of a Sheep
}

\author{
C. HALBERSTADT, Ph.D., ${ }^{1}$ C. AUSTIN, B.S., ${ }^{1}$ J. ROWLEY, M.S., ${ }^{2}$ \\ C. CULBERSON, M.S., ${ }^{1}$ A. LOEBSACK, M.S., ${ }^{1}$ S. WYATT, B.A., ${ }^{1}$ S. COLEMAN, M.S., ${ }^{1}$ \\ L. BLACKSTEN, B.S., ${ }^{1}$ K. BURG, Ph.D., ${ }^{4}$ D. MOONEY, Ph.D., ${ }^{2,3}$ \\ and W. HOLDER, Jr., M.D. ${ }^{1}$
}

\begin{abstract}
Soft tissue reconstruction using tissue-engineered constructs requires the development of materials that are biocompatible and support cell adhesion and growth. The objective of this study was to evaluate the use of macroporous hydrogel fragments that were formed using either unmodified alginate or alginate covalently linked with the fibronectin cell adhesion peptide RGD (alginate-RGD). These materials were injected into the subcutaneous space of adult, domesticated female sheep and harvested for histological comparisons at 1 and 3 months. In addition, the alginate-RGD porous fragments were seeded with autologous sheep preadipocytes isolated from the omentum, and these cell-based constructs were also implanted. The results from this study indicate that both the alginate and alginate-RGD subcutaneous implants supported tissue and vascular ingrowth. Furthermore, at all time points of the experiment, a minimal inflammatory response and capsule formation surrounding the implant were observed. The implanted materials also maintained their sizes over the 3-month study period. In addition, the alginate-RGD fragments supported the adhesion and proliferation of sheep preadipocytes, and adipose tissue was present within the transplant site of these cellular constructs, which was not present within the biomaterial control sites.
\end{abstract}

\section{INTRODUCTION}

$\mathbf{M}$ UCH RESEARCH HAS FOCUSED on tissue-engineered constructs for the replacement of skin,,${ }^{1,2}$ cartilage, ${ }^{3-6}$ bone, ${ }^{7,8}$ liver, ${ }^{9-12}$ and other tissues. However, little research has involved the development of cellbased biomaterials for reconstruction of soft tissue defects caused by trauma and/or cancer. The goal of using a cell-based biomaterial for reconstructive surgery is to create tissue from transplanted cells that will mimic the shape, structure, and tactile properties of the surrounding native tissue. Cell-based biomaterials

\footnotetext{
${ }^{1}$ General Surgery Research, Carolinas Medical Center, Charlotte, North Carolina.

${ }^{2}$ Department of Chemical Engineering, University of Michigan, Ann Arbor, Michigan.

${ }^{3}$ Dental School, University of Michigan, Ann Arbor, Michigan.

${ }^{4}$ Department of Bioengineering, Clemson University, Clemson, South Carolina.
} 
have the potential to replace the materials currently used such as silicone implants, ${ }^{13,14}$ type I collagen for tissue bulking, ${ }^{15,16}$ and autologous tissue used for free muscle flaps. ${ }^{17,18}$ These approaches have various complications, including (1) the formation of a fibrotic capsule ${ }^{14}$ and possible autoimmune complications; ${ }^{14}$ (2) the absorption of the type I collagen ${ }^{15}$ and (3) the complex surgical procedure of the muscle flap with possible tissue necrosis. ${ }^{18}$

Successful biomaterial constructs for soft tissue engineering must support cellular adhesion, promote rapid vascular and tissue ingrowth throughout the implant site, and induce a minimal fibrotic capsule and inflammatory response. In addition, it is preferable for the material to be delivered using a minimally invasive procedure. Several approaches have been developed toward creating biomaterials that support cell adhesion. ${ }^{19-22}$ However, none of these materials have been used for the delivery of cells for the creation of a soft tissue.

Our group has focused on using a hydrogel material that supports the delivery of cells such as preadipocytes and aids in establishing long-term integration of the cellular implant with the surrounding host tissue. Our previous work described the use of an alginate (a naturally derived hydrogel) material that is covalently modified with a fibronectin cell adhesion peptide, arginine, glycine, and aspartic acid (RGD). ${ }^{23}$ This material was manufactured into a macroporous bead that supported cell attachment, adhesion, and proliferation. ${ }^{24}$ Small animal studies performed over 6 months demonstrated that the material implanted into a subcutaneous space supported tissue ingrowth with a minimal capsule surrounding the implant, and a minor inflammatory response. ${ }^{25}$ In addition, the material retained its shape over the time of the experiment.

To determine whether this material was useful for clinical applications, we conducted a large animal study using a sheep model. Our goal was to determine whether injectable porous hydrogel fragments integrated with the surrounding subcutaneous tissue and whether the tissue formed within the materials was dependent on the presence of the RGD peptide. An additional objective was to demonstrate whether the alginate-RGD porous fragments supported sheep preadipocyte cellular adhesion and growth and whether these cell-based fragments supported the development of new adipose tissue within the transplanted site. It is our goal to use data generated from these and our previous experiments to develop cell-based biomaterials that can be used for the reconstruction of soft tissue defects.

\section{MATERIALS AND METHODS}

\section{Biomaterial processing}

Ultrapure alginate (medium viscosity [MV]; Pronova, lot no. 411-256-05, Portsmouth, NH) was either covalently modified with the GGGGRGDY peptide sequence ${ }^{23}$ or used in an unmodified form. The alginate material was then processed into porous beads as previously described. ${ }^{24,26}$ Fragments were made by placing $50-\mathrm{mL}$ porous beads $/ 250 \mathrm{~mL}$ of deionized water mixture into a blender (Osterizer Galaxie, Oster, Inc.) and processed using the chop speed for approximately $30 \mathrm{sec}$. The fragments were sieved using a 425$\mu \mathrm{m}$ pore filter (no. 40, 35-mesh filter; Fisher Scientific, Pittsburgh, PA), and then removed from the filter (consisting of approximately $500 \mu \mathrm{m}$ in dimension), and placed into 50-mL conical tubes, each containing $10 \mathrm{~mL}$ of fragments in $30 \mathrm{~mL}$ of $0.05 \mathrm{M}$ calcium chloride. The tubes containing the fragments were sterilized using a 1.5-Mrad dose (University of Michigan, Gamma Irradiation Facility). Figure 1a is a confocal microscope image of a fragment that has been stained with eosin (Leica SPF Confocal Laser Scanning Microscope, $5 \times$ magnification, Leica Microsystems, Inc., Exton, PA).

\section{Animal surgery}

Adult domesticated female sheep were used for this study. All experimental procedures were performed in an AAALAC-approved vivarium following Institutional Animal Care and Use Committee guidelines. Each sheep had two surgical procedures. The first procedure was a mini-laparotomy to harvest adipose tissue from the omentum. Isoflurane was used as a general anesthetic.

The second surgical procedure, which took place at least 6 weeks after the initial tissue harvest, was the biomaterial implantation. The sterile fragments were incubated overnight at $37^{\circ} \mathrm{C}$ in Dulbecco's Modified 


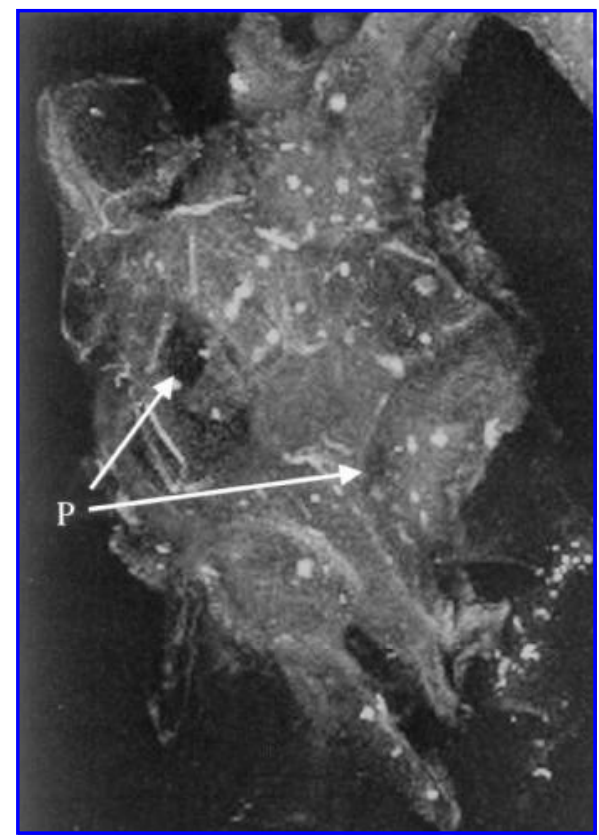

FIG. 1. (a) Laser scanning confocal microscope image of porous alginate fragments. Fragments were stained with eosin $(5 \times$ magnification). (b) 2 -mL injections of fragments into the nape of the neck of a sheep. Four injections were made on each side of the neck.

a

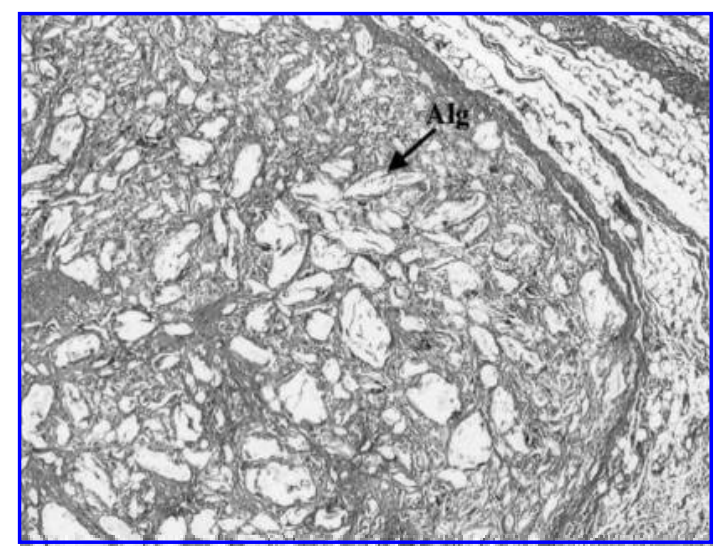

c

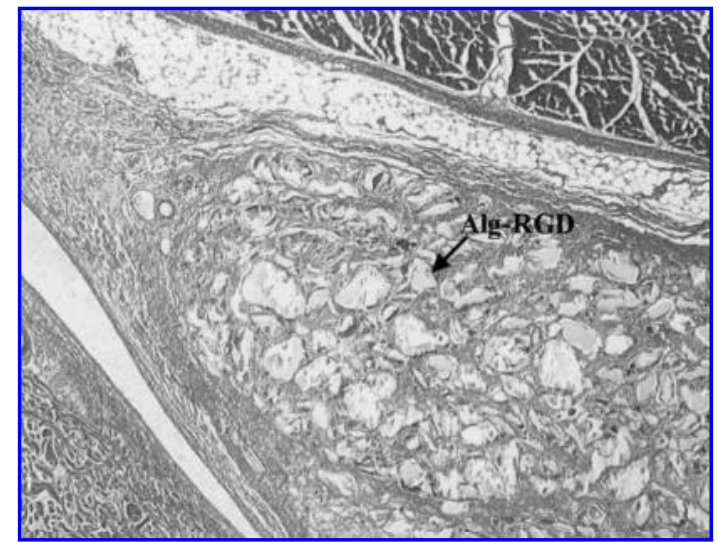

b

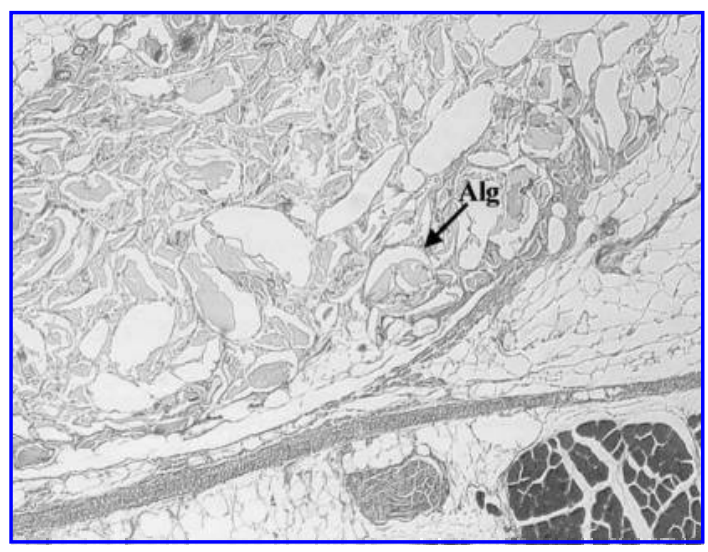

d

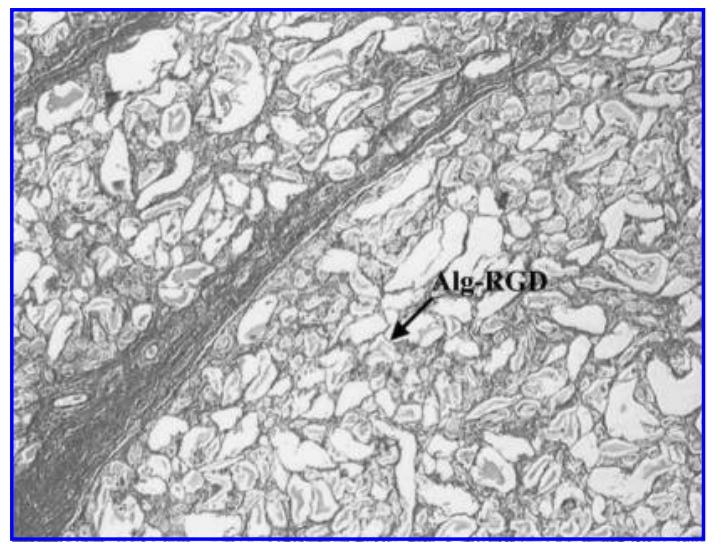

FIG. 2. Histological images (Masson's Trichrome stain) of alginate and alginate-RGD subcutaneous implants (50 $\times$ magnification). Arrow indicates alginate material (alg). (a) 1-month alginate. (b) 3-month alginate. (c) 1-month alginate-RGD. (d) 3-month alginate-RGD. 
Eagles Media (DMEMc; Fisher Scientific) containing 1\% fetal bovine serum (FBS, Sigma-Aldrich, St. Louis, MO). Before the surgical procedure, the fragments were measured into 1-mL aliquots and then combined with $1 \mathrm{~mL}$ of DMEMc and loaded into a 5-mL syringe (Becton Dickinson and Company, Franklin Lakes, NJ). With the sheep under general anesthesia, a 2-mL total volume of material was injected into the nape of the neck with an 18-gauge needle (a maximum of four injections in each side of the neck; Fig. 1b). The widths of the implants were measured weekly using a GE LOGIQ 500 MR3 ultrasound with the H7039ML Linear LA39 probe (General Electric Medical, Milwaukee, WI) that emitted a frequency of 7.5 MHz.

\section{Cell isolation, proliferation, and seeding onto biomaterials}

Harvested omentum was placed into transport solution (TS) containing Hanks' balanced salt solution without calcium and without magnesium (Fisher Scientific) to which was added amphotericin B (10 $\mu \mathrm{g} / \mathrm{mL}$; Sigma-Aldrich) and penicillin-streptomycin (100 Units $/ \mathrm{mL}$ and $100 \mu \mathrm{g} / \mathrm{mL}$, respectively; SigmaAldrich). The tissue was rinsed three times with the TS, placed into $5 \mathrm{ml}$ of TS, and minced with small scissors into 1- to 2-mm pieces. A maximum of $5 \mathrm{ml}$ of minced tissue was transferred per $50-\mathrm{mL}$ tube containing $20 \mathrm{~mL}$ of enzyme solution. The enzyme solution consisted of $4 \mathrm{mg} / \mathrm{mL}$ Collagenase I (Worthington Biochemical Corp., Lakewood, $\mathrm{NJ}$ ) and $2 \mathrm{mg} / \mathrm{mL}$ bovine serum albumin (BSA, Sigma-Aldrich) in TS. The tube was agitated on its side at $37^{\circ} \mathrm{C}$ in $5 \% \mathrm{CO}_{2}$ on an orbital shaker at $85-95 \mathrm{rpm}$ for 45 min or until approximately $1 \%$ of the original tissue was visible. Using a 5-mL syringe (Sherwood Medical, St. Louis, MO) fitted with a 15-gauge needle (Sherwood Medical), the enzyme mixture was triturated three to five times and subjected to centrifugation at $800 \times g$ for $10 \mathrm{~min}$. The fat and aqueous layers were aspirated, and the cell pellet was suspended in $20 \mathrm{ml}$ of red blood cell lysis buffer $(0.154 \mathrm{M}$ $\mathrm{NH}_{4} \mathrm{CL}, 10 \mathrm{mM} \mathrm{KHCO} 2,0.1 \mathrm{mM}$ EDTA, Sigma-Aldrich) and allowed to incubate for $10 \mathrm{~min}$ at room temperature. The suspension was then passed through a 40- $\mu$ m nylon sieve (Fisher Scientific) and subjected to centrifugation at $800 \times g$ for $10 \mathrm{~min}$. The cells were washed once in $20 \mathrm{ml}$ of TS and plated in DMEM (Fisher Scientific) supplemented with 10\% FBS (Sigma-Aldrich), Insulin-Transferin-Selenium $(0.01 \mu \mathrm{g} / \mathrm{mL}, 0.05 \mu \mathrm{g} / \mathrm{mL}$, and $0.05 \mathrm{ng} / \mathrm{mL}$, respectively; Sigma-Aldrich), $0.02 \mu \mathrm{g} / \mathrm{mL}$ FGF (Sigma-Aldrich), $2 \mathrm{mM}$ L-glutamine (Life Technologies, Rockville, MD), $2.5 \mu \mathrm{g} / \mathrm{mL}$ amphotericin B (Sigma-Aldrich), and penicillin-streptomycin (100 Units/mL and $100 \mu \mathrm{g} / \mathrm{mL}$, respectively; SigmaAldrich). The cells were then expanded in culture using the media described above. After five passages, the cells were seeded at a concentration of $3.0 \times 10^{6}$ cells $/ \mathrm{mL}$ per $10 \mathrm{~mL}$ of alginate-RGD fragments in a roller bottle $\left(850 \mathrm{~cm}^{2}\right.$; Fisher Scientific) that was pretreated overnight at $4{ }^{\circ} \mathrm{C}$ with $3 \%$ BSA (SigmaAldrich) and then rinsed prior to use with sterile phosphate-buffered saline (Sigma-Aldrich). The roller bottle was rotated at $1.2 \mathrm{rpm}$, and the fragments were harvested 5 days postseeding. Cell viability was determined using fluorescent viability dyes of calcein AM and Ethidium homodimer-1 (Live/Dead ${ }^{\text {TM }}$ kit from Molecular Probes, Inc., Eugene, OR), and three-dimensional images were captured using a Leica confocal microscope. Calcein AM emits a green fluorescence when cleaved by esterase in live cells (excitation of $495 \mathrm{~nm}$ and emission of $515 \mathrm{~nm}$ ). Ethidium homodimer-1 emits a red fluorescence and only enters dead or dying cells (excitation of $495 \mathrm{~nm}$ and emission of $635 \mathrm{~nm}$ ). Only four of six sheep yielded sufficient preadipocytes to seed onto biomaterials and inject into the subcutaneous space of the neck.

\section{Tissue harvesting and histological processing}

To evaluate all of the biomaterial implants, three animals were euthanized 1 month postinjection and three animals were euthanized 3 months postinjection. The implants were identified using ultrasound before euthanasia ${ }^{23}$ and then harvested with a surrounding margin of connective tissue. The tissues were placed into Z-fix formalin (Anatech Ltd., Battle Creek, MI) and allowed to fix for a minimum of $48 \mathrm{~h}$. The fixed tissue samples were cut in half at the mid-line to preserve the tissue biomaterial interface. These cut tissue blocks were processed using a paraffin embedding method. Four-micron sections were cut through the polymer-containing tissue perpendicular to the skin and muscle and stained with hematoxylin and eosin (H\&E; Allegiance, McGraw Park, IL) and Masson's Trichrome (MT; PolyScientific, Bay Shore, NY) for the detection of collagen. 


\section{Data quantification}

Histology slides for the injected alginate and alginate-RGD fragments were reviewed by two investigators and were scored using a scale of 0 for a minimal and 4 for a maximum response. ${ }^{25}$ The slides were assessed for tissue ingrowth into the polymer substrate, vascular ingrowth into the implanted material, inflammatory response (giant cells, monocytes, and polymorphonuclear leukocytes [PMNs]), and capsule formation around the perimeter of the implant. Images of each slide were captured using an Olympus BX40 inverted microscope (Olympus Optical Incorporated, Japan) with a Sony PowerHAD 3CCD color video camera (DXC-950P, Sony, Inc., Japan) and the data processed using a Dell Dimension XPS R450 computer. The captured data were imported into Image Pro 4.0 (Media Cybernetics, Silver Spring, MD), and the width and area of the implants were measured.

\section{Statistical analysis}

Means and standard errors were calculated for all data, and an analysis of variance (ANOVA) was calculated using Scheffe's analysis and Statview, version $4.5^{\circledR}$ (Abacus, Berkeley, CA). Differences were deemed significant at a $95 \%$ confidence level $(p<0.05)$.
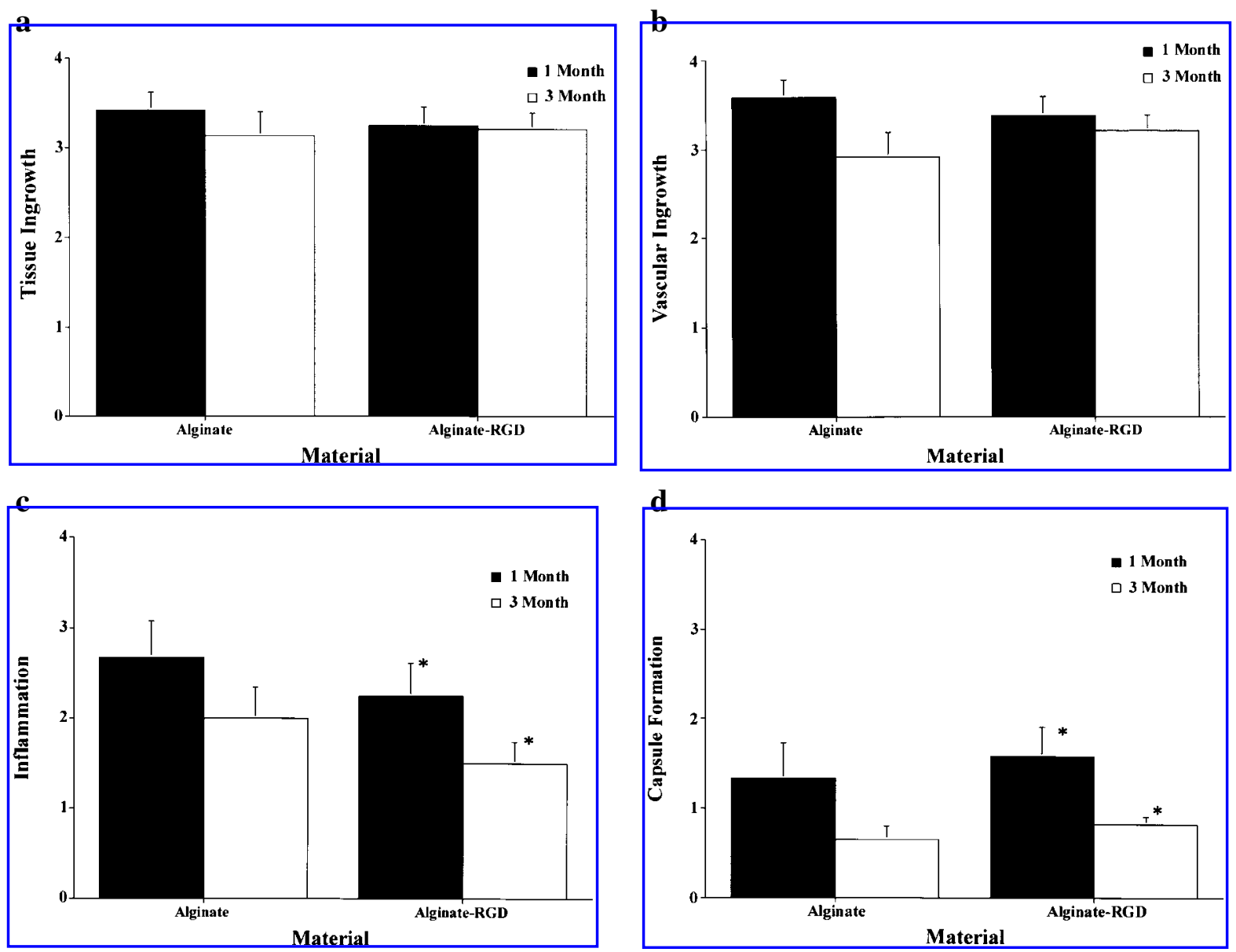

FIG. 3. Histological scoring of alginate and alginate-RGD implants at 1 and 3 months. (a) Tissue ingrowth. (b) Vascular ingrowth. (c) Inflammation. (d) Capsule formation around the implant ( $n=6$ for 1- and 3-month alginate and 1month alginate-RGD; $n=7$ for alginate-RGD 3-month implants). *Statistical significance $p<0.05$. 


\section{HALBERSTADT ET AL.}

\section{RESULTS}

The 2-mL injection of biomaterial plus DMEMc into the sheep's neck created a raised bleb within the subcutaneous space (Fig. 1b) that decreased in size by the fourth to fifth week due to the loss of fluid injected with the hydrogel fragments. It is unclear whether the fluid injected with the fragments had any bearing on tissue engraftment since all of the implants were injected using the same solution.

$\mathbf{a}$

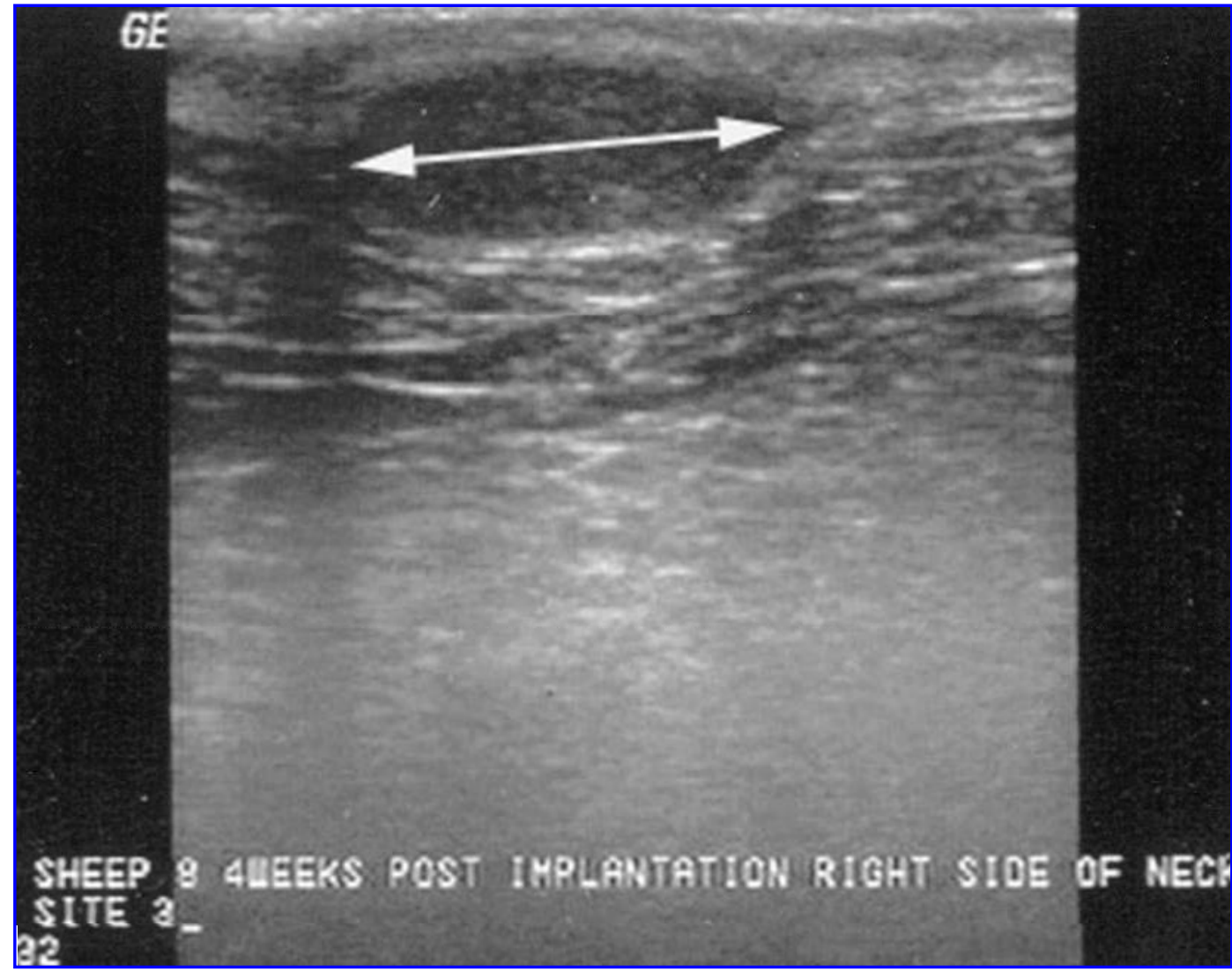

b

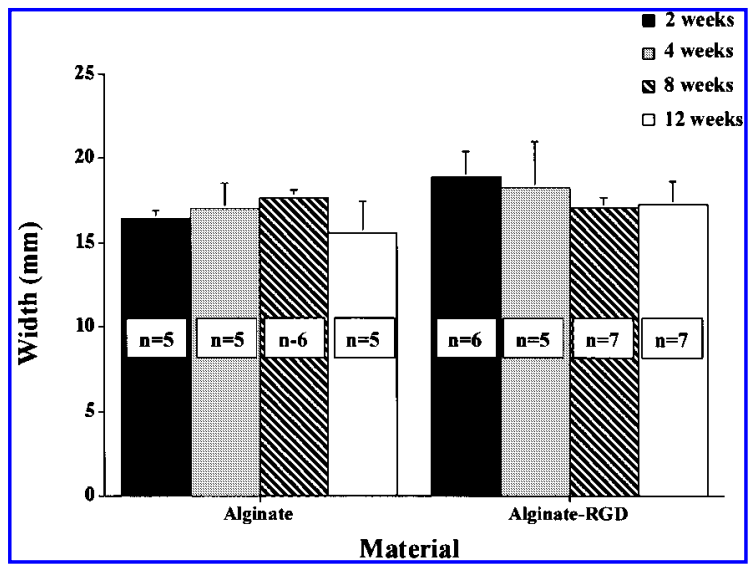

FIG. 4. (a) Ultrasound image of subcutaneous alginate fragment implant taken at 3 months. Arrow indicates width of implant. (b) Width (mm) of alginate and alginate-RGD implants measured using ultrasound over 12 weeks. 
Representative histology slides for the alginate and alginate-RGD implants from 1 and 3 months are presented in Fig. 2a-d. Tissue and vascular ingrowth with a minimal capsule surrounding the materials is evident in all of the implant sites. The alginate and alginate-RGD are still present within the subcutaneous space at 3 months. Figure 3 presents the data generated from the scoring evaluation $(0=$ minimal and $4=$ maximal). There was no statistical difference between the two materials in tissue ingrowth, and the ingrowth remained constant throughout the experiment (Fig. 3a). There was a well-established vascular bed in both materials (Fig. 3b), and there was no statistical change in vascular ingrowth over the time of the experiment. The inflammatory response, consisting mainly of giant cells and monocytes within the implant site, was more prominent at 1 month, and there was a statistically significant decrease between the 1- and 3month time points for the alginate-RGD implant site (Fig. 3c). The inflammatory response was similar in magnitude for all of the conditions examined and could be due to the alginate, the DMEMc carrier solution, or a combination of both the hydrogel and the media. Weakly organized collagen surrounding the material implants was defined as the implant capsule and was noted to be minimal for both materials at 1 and 3 months (Fig. 3d). There was a significant decrease in the presence of a capsule for the alginate-RGD implants, with some grafts demonstrating complete integration with the surrounding tissue.

The width of the implants was examined weekly using high-frequency ultrasound. ${ }^{27}$ Figure $4 \mathrm{a}$ is an ultrasound image of a 12-week alginate implant. The width of the implant was quantified using the ultrasound machine software. There was no statistical difference in implant width when comparing the two materials, and the width of the implants did not change during the experiment (Fig. 4b).

To confirm the ultrasound measurements, histology slides of both materials from the 1- and 3-month time points were measured for width and total area using an image analysis system. Again, there was no statistical difference in width or area for either material throughout the study (Fig. 5a,b). The widths measured on the histology slides were less than those measured by ultrasound, which could be due to the $15-30 \%$ shrinkage of the tissue that occurs during histological processing. ${ }^{28,29}$

Sheep preadipocytes isolated from the omentum, expanded in culture, and seeded onto the porous alginate-RGD fragments are shown in Figure 6. The sheep preadipocytes attached, proliferated, and spread onto the biomaterial surface. This material was subsequently implanted into the nape of the neck of some of the sheep to determine if new adipose tissue would form. Photomicrographs of histology slides of 1- and 3month implantations are presented in Figure $7 \mathrm{a}-\mathrm{d}$. Well-defined adipose tissue was identified in the biomaterial transplant site. This was not observed in any of the acellular biomaterial implants. However, it is unknown whether the observed adipose tissue was due to the transplanted cells or new tissue ingrowth from the surrounding subcutaneous space.
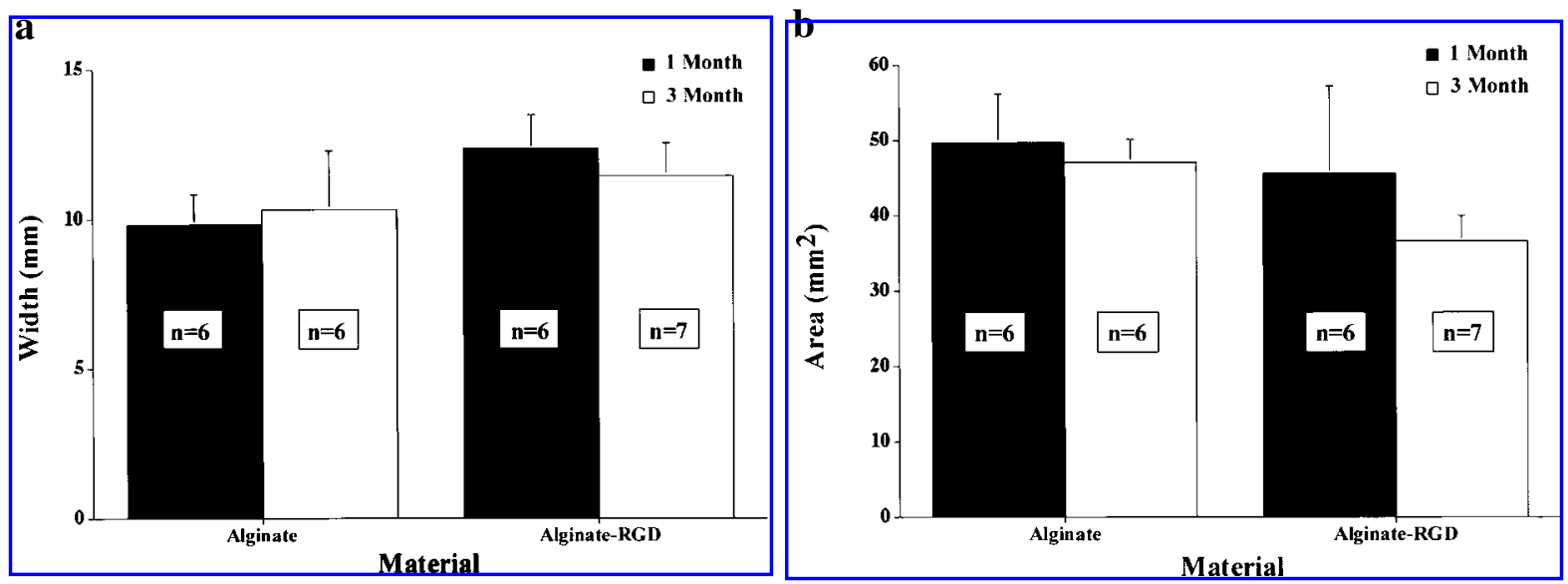

FIG. 5. (a) Width ( $\mathrm{mm})$ of alginate and alginate-RGD implants measured at 1 and 3 months on histology slides. (b) Area $\left(\mathrm{mm}^{2}\right)$ of alginate and alginate-RGD implants measured at 1 and 3 months on histology slides. 


\section{DISCUSSION}

Both alginate and alginate-RGD injected into the subcutaneous space of the sheep's neck demonstrated minimal capsule formation, mild inflammatory response, and excellent tissue and vascular ingrowth throughout the interstices of the material. These are important observations because very few materials elicit a similar response in a subcutaneous implant site.

To be a useful material for a plastic and reconstructive construct, the implant must remain stable for an extended time. Our previous work with a rat subcutaneous implant model demonstrated that alginate was still present at 6 months, and the area of the implant did not change over this time. ${ }^{25}$ To determine the width and presence of the implants over the course of the sheep experiment, we used high-frequency ultrasound. ${ }^{27}$ High frequency ultrasound provided us the ability to monitor noninvasively the subcutaneous biomaterial implants over time. The implanted biomaterials are denser than the surrounding subcutaneous tissue. Hence, the emitted sound waves from the transducer reflect off of the biomaterial and are detected by the transducer that then depicts the implanted material as a shadow compared with the surrounding tissue. Both the ultrasound and corresponding histology measurements demonstrate that the material retains its shape and structure over the experiment.

To use this material for cell transplantation, the hydrogel structure must support cellular adhesion and growth. Previous work has demonstrated that this material supports murine cell adhesion and proliferation. ${ }^{23,24,30}$ In the present study, we conducted initial experiments to isolate adipose tissue from the omentum of the sheep, expanded the cells, and seeded the pre-adipocytes onto the alginate-RGD porous fragments. The omentum was chosen as the adipose tissue source because of the lack of adequate subcutaneous adipose tissue. Using the omentum as the adipose tissue source, we had variable results in the isolation and expansion of preadipocytes, with two of six sheep yielding too few cells for a cell seeding and transplant experiment. This lack of a good subcutaneous adipose tissue supply hampers further use of the sheep for this study. Nevertheless, sites transplanted with preadipocyte/alginate-RGD constructs (Fig. 7a-d) appear to have adipose tissue closely associated with the material. This tissue structure was not observed in any of the alginate or alginate-RGD control implantation sites. Unfortunately, we cannot conclusively state that the adipose tissue observed is due to the transplanted cells. This is due to the implantation of autologous preadipocytes into an area that contains adipocytes. To solve this problem, a traceable marker, such as a transfected cell expressing green fluorescent protein or a fluorescent tracking dye, should be used. Additional work using a different large animal model must be performed to determine whether adipose tissue can be reproducibly developed within the transplant site.

\section{CONCLUSION}

This study examined the use of a naturally derived hydrogel material to engraft in the subcutaneous space of a sheep and incorporate with the surrounding host tissue. Both alginate and alginate-RGD elicited a mild inflammatory response and incorporated well with the surrounding host tissue. However, as we demonstrated here and previously, ${ }^{23,30}$ alginate-RGD provided the advantage of promoting cellular adhesion and proliferation ex vivo. Hence, alginate-RGD provided the properties necessary for the success of constructs for soft tissue reconstruction.

FIG. 6. Confocal image of sheep preadipocytes seeded onto porous alginate-RGD fragments. Viable cells are stained with Calcein AM that emits a fluorescent green upon excitation (excitation of $495 \mathrm{~nm}$ and emission of $515 \mathrm{~nm}$ ). Dead cells are stained with Ethidium homodimer-1 that emits a red fluorescence (excitation of $495 \mathrm{~nm}$ and emission of 635 $\mathrm{nm})$. Magnification, $5 \times$.

FIG. 7. (a) 1 -month implantation of sheep preadipocyte seeded alginate-RGD fragments ( $40 \times$ magnification). (b) 1 month implantation of sheep preadipocyte seeded alginate-RGD fragments (200× magnification). (c) 3-month implantation of sheep preadipocyte seeded alginate-RGD fragments (40× magnification). (d) 3-month implantation of sheep preadipocyte seeded alginate-RGD fragments (200× magnification). 


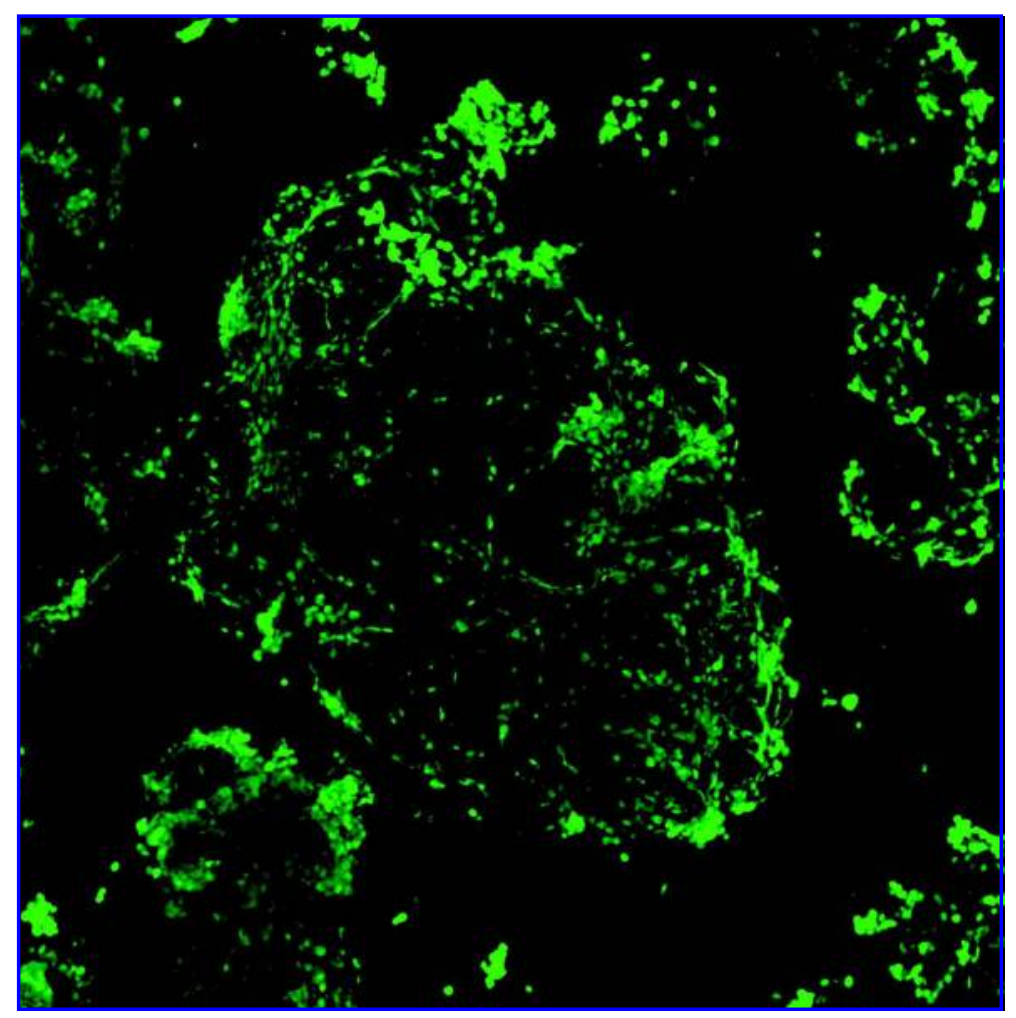

FIG. 6.

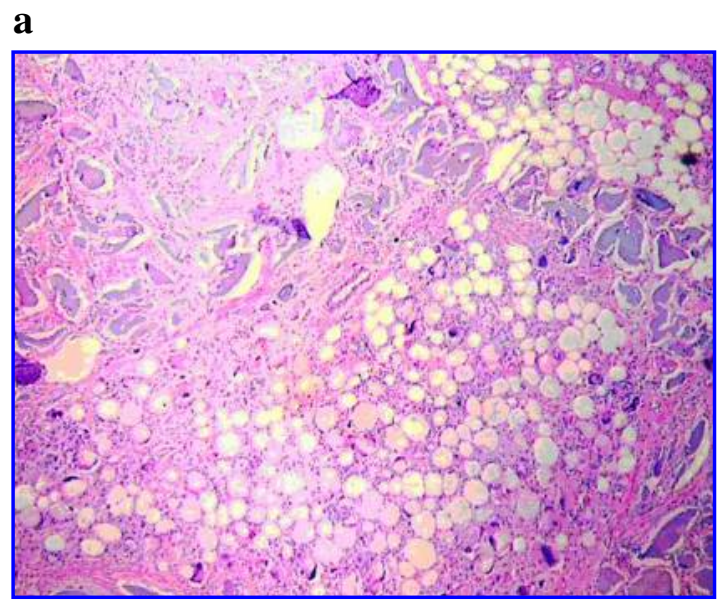

b
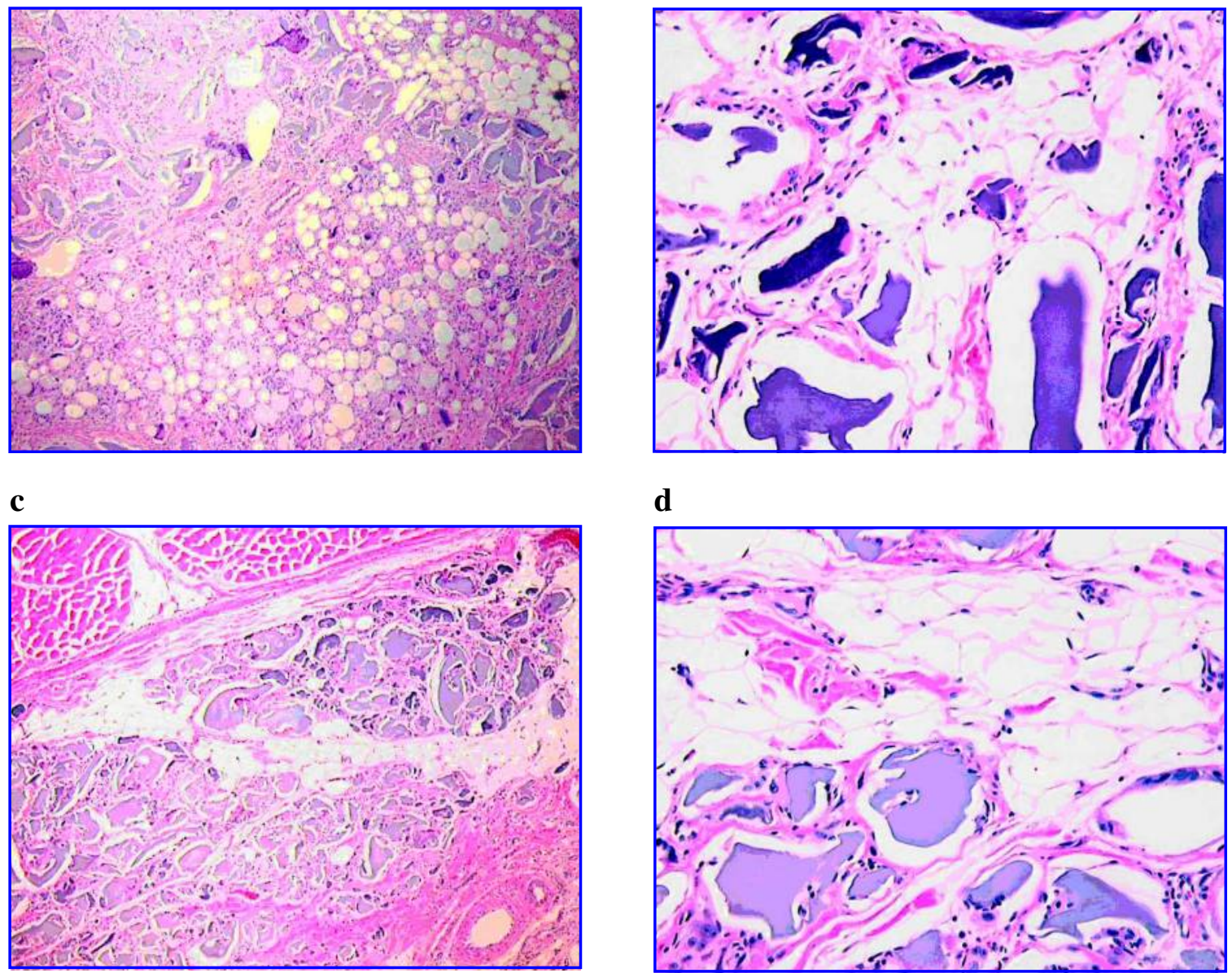

d

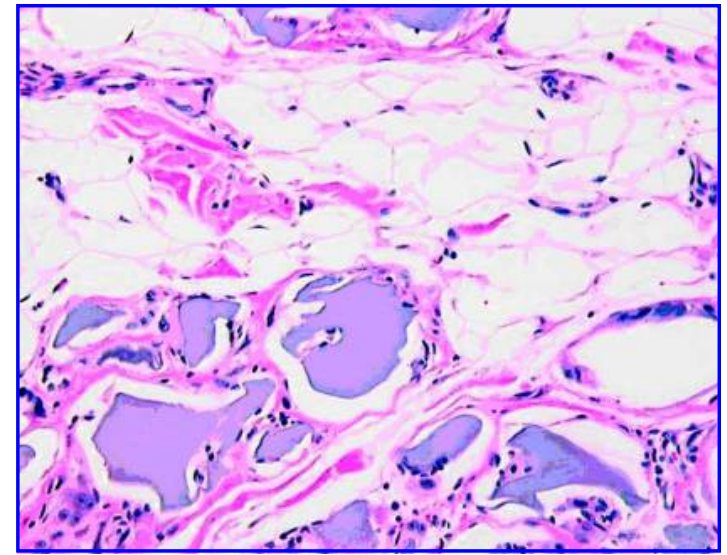

FIG. 7. 
The long-term focus of our research is to develop subcutaneous tissue implants for the reconstruction of soft tissue defects. A specific goal is to develop an implant suitable for those who have had breast tissue removed (lumpectomy) for the treatment of breast cancer. Currently, there is no reconstructive option for these patients and therefore, many patients choose to have a mastectomy with total breast reconstruction. Our group is currently able to isolate, expand, and differentiate human preadipocytes from fat derived from a lipoaspirate. Our hope is that alginate-RGD in combination with autologous preadipocytes isolated from lipoaspirate can eliminate complex surgical procedures by providing an implant that will form new tissue and provide lumpectomy patients a reconstructive option.

\section{ACKNOWLEDGMENTS}

We thank the Health Services Foundation of the Carolinas Medical Center and Reprogenesis, Inc. for their financial support and Cissy Swartz for her review of the manuscript. This work was presented in part at the third biennial meeting of the Tissue Engineering Society, Orlando, Florida, November 30 through December 3, 2000.

\section{REFERENCES}

1. Parenteau, N. Skin: the first tissue-engineered products. Sci. Am. 280, 83, 1999.

2. Hansbrough, J.F., Cooper, M.L., Cohen, R., et al. Evaluation of a biodegradable matrix containing cultured human fibroblasts as a dermal replacement beneath meshed skin grafts on athymic mice. Surgery 111, 438, 1992.

3. Kim, W.S., Vacanti, J.P., Cima, L., et al. Cartilage engineered in predetermined shapes employing cell transplantation on synthetic biodegradable polymers. Plast. Reconstr. Surg. 94, 233, 1994.

4. Puelacher, W.C., Kim, S.W., Vacanti, J.P., et al. Tissue-engineered growth of cartilage: the effect of varying the concentration of chondrocytes seeded into synthetic polymer matrices. Int. J. Oral. Maxillofac. Surg. 23, 49, 1994.

5. Wakitani, S., Goto, T., Young, R.G., et al. Repair of large full-thickness articular cartilage defects with allograft articular chondrocytes embedded in a collagen gel. Tissue. Eng. 4, 429, 1998.

6. Grande, D.A., Halberstadt, C., Naughton, G., et al. Evaluation of matrix scaffolds for tissue engineering of articular cartilage grafts. J. Biomed. Mater. Res. 34, 211, 1997.

7. Peter, S.J., Miller, M.J., Yasko, A.W., et al. Polymer concepts in tissue engineering. J. Biomed. Mater. Res. 43, 422, 1998.

8. Vacanti, C.A., Kim, W., Upton, J., et al. Tissue-engineered growth of bone and cartilage. Transplant. Proc. 25, 1019, 1993.

9. Mooney, D.J., Kaufmann, P.M., Sano, K., et al. Transplantation of hepatocytes using porous, biodegradablesponges. Transplant. Proc. 26, 3425, 1994.

10. Naughton, B.A., Sibanda, B., Weintraub, J.P., et al. A stereotypic, transplantable liver tissue-culture system. Appl. Biochem. Biotechnol. 54, 65, 1995.

11. Fontaine, M., Schloo, B., Jenkins, R., et al. Human hepatocyte isolation and transplantation into an athymic rat, using prevascularized cell polymer constructs. J. Pediatr. Surg. 30, 56, 1995.

12. Griffith, L.G., Wu, B., Cima, M.J., et al. In vitro organogenesis of liver tissue. Ann. N.Y. Acad. Sci. 831, 382, 1997.

13. Wyatt, L.E., Sinow, J.D., Wollman, J.S., et al. The influence of time of human breast capsule histology: smooth and textured silicone-surfaced implants. Plast. Reconstr. Surg. 102, 1922, 1998.

14. Shanklin, D.R., and Smallley, D.L. Dynamics of wound healing after silicone device implantation. Exp. Mol. Pathol. 67, 26, 1999.

15. Hoffmann, C., Schuller-Petrovic, S., Soyer, H.P., et al. Adverse reactions after cosmetic lip augmentation with permanent biologically inert implant materials. J. Am. Acad. Dermatol. 40, 100, 1999.

16. Ozgentas, H.E., Pindur, A., Spira, M., et al. A comparison of soft-tissue substitutes. Ann. Plast. Surg. 33, 171, 1994.

17. Clugston, P.A., Gingrass, M.K., Azurin, D., et al. Ipsilateral pedicled TRAM flaps: the safer alternative? $\underline{\text { Plast. Re- }}$ constr. Surg. 105, 77, 2000.

18. Arnez, Z.M., Khan, U., Pogorelec, D., et al. Rational selection of flaps from the abdomen in breast reconstruction to reduce donor site morbidity. Br. J. Plast. Surg. 52, 351, 1999. 
19. Massia, S.P., and Hubbell, J.A. Covalent surface immobilization of Arg-Gly-Asp- and Tyr-Ile-Gly-Ser-Arg-containing peptides to obtain well-defined cell-adhesive substrates. Anal. Biochem. 187, 292, 1990.

20. Hern, D.L., and Hubbell, J.A. Incorporation of adhesion peptides into nonadhesive hydrogels useful for tissue resurfacing. J. Biomed. Mater. Res. 39, 266, 1998.

21. Kao, W.J., and Hubbell, J.A. Murine macrophage behavior on peptide-grafted polyethyleneglycd-containing networks. Biotechnol. Bioeng. 59, 2, 1998.

22. Urry, D.W., Pattanaik, A., Xu, J., et al. Elastic protein-based polymers in soft tissue augmentation and generation. J. Biomater. Sci. Polym. Ed. 9, 1015, 1998.

23. Rowley, J.A., Madlambayan, G., and Mooney, D.J. Alginate hydrogels as synthetic extracellular matrix materials. Biomaterials 20, 45, 1999.

24. Eiselt, P., Yeh, J., Latvala, R.K., et al. Porous carriers for biomedical applications based on alginate hydrogels. Biomaterials 21, 1921, 2000.

25. Halberstadt, C.R., Mooney, D.J., Burg, K.J.L., et al. The design and implementation of an alginate material for soft tissue engineering. Presented at the Sixth World Biomaterial Congress, 2000.

26. Burg, K.J.L., Austin, C.E., Mooney, D.J., et al. Optimizing microstructure of porous alginate-RGD beads for tissue engineering applications. Presented at the Sixth World Biomaterials Congress, 2000.

27. Austin, C., Greene, K., Culberson, C., et al. Ultrasound as a noninvasive method to monitor biodegradable, subcutaneous implants in animal models. Tissue Eng. 6, 662, 2000.

28. Stickland, N.C. A detailed analysis of the effects of various fixatives on animal tissue with particular reference to muscle tissue. Stain Technol. 50, 255, 1975.

29. Lum, H., and Mitzner, W. Effects of $10 \%$ formalin fixation on fixed lung volume and lung tissue shrinkage. A comparison of eleven laboratory species. Am. Rev. Respir. Dis. 132, 1078, 1985.

30. Greene, K.G., Burg, K.J.L., Austin, C.E., et al. The development of a seeding method for a porous hydrogel construct. Presented at the Sixth World Biomaterials Congress, 2000.

Address reprint requests to:

Craig Halberstadt, Ph.D.

General Surgery Research

Cannon Research Building

Carolinas Medical Center

P.O. Box 32861

Charlotte, NC 28232-2861

E-mail: chalberstadt@ carolinas.org 


\section{This article has been cited by:}

1. Michael R. Buchmeiser. 2009. Monolithic biocompatible and biodegradable scaffolds for tissue engineering. Journal of Polymer Science Part A: Polymer Chemistry 47:9, 2219-2227. [CrossRef]

2. Nokyoung Park, Soong Ho Um, Hisakage Funabashi, Jianfeng Xu, Dan Luo. 2009. A cell-free protein-producing gel. Nature Materials 8:5, 432-437. [CrossRef]

3. Philip V. Peplow, George J. Dias, Fernanda Teixeira, Robert J. Kelly. 2009. Tissue reaction to matrices of reconstituted keratin polymer implanted subcutaneously in sheep. Journal of Biomedical Materials Research Part A 89A:1, 255-265. [CrossRef]

4. Michelle Locke, John Windsor, P. Rod Dunbar. 2009. Human adipose-derived stem cells: isolation, characterization and applications in surgery. ANZ Journal of Surgery 79:4, 235-244. [CrossRef]

5. David E. Orr, Karen J. L. Burg. 2008. Design of a Modular Bioreactor to Incorporate Both Perfusion Flow and Hydrostatic Compression for Tissue Engineering Applications. Annals of Biomedical Engineering 36:7, 1228-1241. [CrossRef]

6. Charles W. Patrick Jr. , Rajesh Uthamanthil , Elisabeth Beahm , Cindy Frye . 2008. Animal Models for Adipose Tissue EngineeringAnimal Models for Adipose Tissue Engineering. Tissue Engineering Part B: Reviews 14:2, 167-178. [Abstract] [PDF] [PDF Plus]

7. Barbara Weiser , Lukas Prantl , Thomas E.O. Schubert , Johannes Zellner , Claudia Fischbach-Teschl, Thilo Spruss, Anna K. Seitz , Joerg Tessmar , Achim Goepferich , Torsten Blunk . 2008. In Vivo Development and Long-Term Survival of Engineered Adipose Tissue Depend on In Vitro Precultivation StrategyIn Vivo Development and Long-Term Survival of Engineered Adipose Tissue Depend on In Vitro Precultivation Strategy. Tissue Engineering Part A 14:2, 275-284. [Abstract] [PDF] [PDF Plus]

8. Hiroshi Mizuno, Yurie Itoi, Satoko Kawahara, Rei Ogawa, Satoshi Akaishi, Hiko Hyakusoku. 2008. In vivo Adipose Tissue Regeneration by Adipose-Derived Stromal Cells Isolated from GFP Transgenic Mice. Cells Tissues Organs 187:3, 177-185. [CrossRef]

9. Barbara Weiser , Lukas Prantl, Thomas E.O. Schubert, Johannes Zellner , Claudia Fischbach-Teschl, Thilo Spruss, Anna K. Seitz , Joerg Tessmar , Achim Goepferich , Torsten Blunk . In Vivo Development and Long-Term Survival of Engineered Adipose Tissue Depend on In Vitro Precultivation StrategyIn Vivo Development and Long-Term Survival of Engineered Adipose Tissue Depend on In Vitro Precultivation Strategy. Tissue Engineering, ahead of print. [Abstract] [PDF] [PDF Plus]

10. Michael S. Stosich, Barb Bastian, Nicholas W. Marion, Paul A. Clark, Gwendolen Reilly, Jeremy J. Mao . 2007. Vascularized Adipose Tissue Grafts from Human Mesenchymal Stem Cells with Bioactive Cues and Microchannel ConduitsVascularized Adipose Tissue Grafts from Human Mesenchymal Stem Cells with Bioactive Cues and Microchannel Conduits. Tissue Engineering 13:12, 2881-2890. [Abstract] [PDF] [PDF Plus]

11. Nestor Torio-Padron, Niklas Baerlecken, Arash Momeni, G. Bjoern Stark, Joerg Borges. 2007. Engineering of Adipose Tissue by Injection of Human Preadipocytes in Fibrin. Aesthetic Plastic Surgery 31:3, 285-293. [CrossRef]

12. Michael S. Stosich, Jeremy J. Mao. 2007. Adipose Tissue Engineering from Human Adult Stem Cells: Clinical Implications in Plastic and Reconstructive Surgery. Plastic and Reconstructive Surgery 119:1, 71-83. [CrossRef]

13. Craig Halberstadt, Dwaine F Emerich, Ken Gonsalves. 2006. Combining cell therapy and nanotechnology. Expert Opinion on Biological Therapy 6:10, 971-981. [CrossRef] 
14. Karsten Hemmrich, Dennis von Heimburg. 2006. Biomaterials for adipose tissue engineering. Expert Review of Medical Devices 3:5, 635-645. [CrossRef]

15. Darnell Kaigler, Joni A Cirelli, William V Giannobile. 2006. Growth factor delivery for oral and periodontal tissue engineering. Expert Opinion on Drug Delivery 3:5, 647-662. [CrossRef]

16. Alexander D. Augst, Hyun Joon Kong, David J. Mooney. 2006. Alginate Hydrogels as Biomaterials. Macromolecular Bioscience 6:8, 623-633. [CrossRef]

17. Satoko Kawahara, Hiko Hyakusoku, Rei Ogawa, Seiji Ohkubo, Hironaka Igarashi, Keiko Hirakawa. 2006. Clinical Imaging Diagnosis of Implant Materials for Breast Augmentation. Annals of Plastic Surgery 57:1, 6-12. [CrossRef]

18. Zhuo Wang, James Goh, Shamal Das De, Zigang Ge, Hongwei Ouyang, Jeniffer Sue Wee Chong, Siew Leng Low , Eng Hin Lee . 2006. Efficacy of Bone Marrow-Derived Stem Cells in Strengthening Osteoporotic Bone in a Rabbit ModelEfficacy of Bone Marrow-Derived Stem Cells in Strengthening Osteoporotic Bone in a Rabbit Model. Tissue Engineering 12:7, 1753-1761. [Abstract] [PDF] [PDF Plus]

19. Anna M Parker, Adam J Katz. 2006. Adipose-derived stem cells for the regeneration of damaged tissues. Expert Opinion on Biological Therapy 6:6, 567-578. [CrossRef]

20. Zhuo Wang, James Goh, Shamal Das De, Zigang Ge, Hongwei Ouyang, Jeniffer Sue Wee Chong, Siew Leng Low, Eng Hin Lee. 2006. Efficacy of Bone Marrow-Derived Stem Cells in Strengthening Osteoporotic Bone in a Rabbit Model. Tissue Engineering, ahead of print060802052515044. [CrossRef]

21. Markus Neubauer, Michael Hacker, Petra Bauer-Kreisel, Barbara Weiser, Claudia Fischbach , Michaela B Schulz, Achim Goepferich , Torsten Blunk . 2005. Adipose Tissue Engineering Based on Mesenchymal Stem Cells and Basic Fibroblast Growth Factor in VitroAdipose Tissue Engineering Based on Mesenchymal Stem Cells and Basic Fibroblast Growth Factor in Vitro. Tissue Engineering 11:11-12, 1840-1851. [Abstract] [PDF] [PDF Plus]

22. Liu Hong, Ioana Peptan, Paul Clark, Jeremy J. Mao. 2005. Ex Vivo Adipose Tissue Engineering by Human Marrow Stromal Cell Seeded Gelatin Sponge. Annals of Biomedical Engineering 33:4, 511-517. [CrossRef]

23. Adel Alhadlaq, Minghui Tang, Jeremy J. Mao . 2005. Engineered Adipose Tissue from Human Mesenchymal Stem Cells Maintains Predefined Shape and Dimension: Implications in Soft Tissue Augmentation and ReconstructionEngineered Adipose Tissue from Human Mesenchymal Stem Cells Maintains Predefined Shape and Dimension: Implications in Soft Tissue Augmentation and Reconstruction. Tissue Engineering 11:3-4, 556-566. [Abstract] [PDF] [PDF Plus]

24. Teiichi Masuda , Masutaka Furue , Takehisa Matsuda . 2004. Novel Strategy for Soft Tissue Augmentation Based on Transplantation of Fragmented Omentum and PreadipocytesNovel Strategy for Soft Tissue Augmentation Based on Transplantation of Fragmented Omentum and Preadipocytes. Tissue Engineering 10:11-12, 1672-1683. [Abstract] [PDF] [PDF Plus]

25. Charles W. Patrick. 2004. BREAST TISSUE ENGINEERING. Annual Review of Biomedical Engineering 6:1, 109-130. [CrossRef]

26. M.A. Lawson , J.E. Barralet , L. Wang , R.M. Shelton , James T. Triffitt . 2004. Adhesion and Growth of Bone Marrow Stromal Cells on Modified Alginate HydrogelsAdhesion and Growth of Bone Marrow Stromal Cells on Modified Alginate Hydrogels. Tissue Engineering 10:9-10, 1480-1491. [Abstract] [PDF] [PDF Plus] 
27. Amanda J. Thornton, Eben Alsberg, Megan Albertelli, David J. Mooney. 2004. SHAPE-DEFINING SCAFFOLDS FOR MINIMALLY INVASIVE TISSUE ENGINEERING. Transplantation 77:12, 1798-1803. [CrossRef]

28. Teiichi Masuda, Masutaka Furue, Takehisa Matsuda . 2004. Photocured, Styrenated Gelatin-Based Microspheres for de Novo Adipogenesis through Corelease of Basic Fibroblast Growth Factor, Insulin, and Insulin-Like Growth Factor IPhotocured, Styrenated Gelatin-Based Microspheres for de Novo Adipogenesis through Corelease of Basic Fibroblast Growth Factor, Insulin, and Insulin-Like Growth Factor I. Tissue Engineering 10:3-4, 523-535. [Abstract] [PDF] [PDF Plus]

29. Kevin C. Hicok, Tracey V. du Laney, Yang Sheng Zhou, Yuan-Di C. Halvorsen, Daron C. Hitt, Lyndon F. Cooper, Jeffrey M. Gimble . 2004. Human Adipose-Derived Adult Stem Cells Produce Osteoid in VivoHuman Adipose-Derived Adult Stem Cells Produce Osteoid in Vivo. Tissue Engineering 10:3-4, 371-380. [Abstract] [PDF] [PDF Plus]

30. Jeffrey M Gimble. 2003. Adipose tissue-derived therapeutics. Expert Opinion on Biological Therapy 3:5, 705-713. [CrossRef] 